\title{
Making Treatment-Free Remission (TFR) Easier in Chronic Myeloid Leukemia: Fact-Checking and Practical Management Tools
}

\author{
Fausto Castagnetti ${ }^{1,2} \cdot$ Gianni Binotto $^{3} \cdot$ Isabella Capodanno $^{4} \cdot$ Atto Billio $^{5} \cdot$ Elisabetta Calistri ${ }^{6}$. \\ Francesco Cavazzini ${ }^{7}$. Monica Crugnola ${ }^{8}$. Antonella Gozzini ${ }^{9} \cdot$ Gabriele Gugliotta $^{1}$ - Mauro Krampera ${ }^{10}$. \\ Alessandro Lucchesi ${ }^{11}$ - Anna Merli ${ }^{12}$. Maria Cristina Miggiano ${ }^{13}$. Claudia Minotto ${ }^{14}$. Monica Poggiaspalla ${ }^{11}$. \\ Marzia Salvucci ${ }^{15} \cdot$ Barbara Scappini $^{16} \cdot$ Mario Tiribelli $^{17}$. Elena Trabacchi ${ }^{18} \cdot$ Gianantonio Rosti $^{19} \cdot$ Sara Galimberti $^{20}$. \\ Massimiliano Bonifacio ${ }^{10}$
}

Accepted: 20 July 2021 / Published online: 18 October 2021

(c) The Author(s) 2021

\begin{abstract}
In chronic-phase chronic myeloid leukemia (CML), tyrosine kinase inhibitors (TKIs) are the standard of care, and treatmentfree remission (TFR) following the achievement of a stable deep molecular response (DMR) has become, alongside survival, a primary goal for virtually all patients. The GIMEMA CML working party recently suggested that the possibility of achieving TFR cannot be denied to any patient, and proposed specific treatment policies according to the patient's age and risk. However, other international recommendations (including 2020 ELN recommendations) are more focused on survival and provide less detailed suggestions on how to choose first and subsequent lines of treatment. Consequently, some grey areas remain. After literature review, a panel of Italian experts discussed the following controversial issues: (1) early prediction of DMR and TFR: female sex, non-high disease risk score, e14a2 transcript and early MR achievement have been associated with stable DMR, but the lack of these criteria is not sufficient to exclude any patient from TFR; (2) criteria for first and subsequent line therapy choice: a number of patient and drug characteristics have been proposed to make a personalized decision; (3) monitoring of residual disease after discontinuation: after the first 6 months, the frequency of molecular tests can be reduced based on MR4.5 persistence and short turnaround time; (4) prognosis of TFR: therapy and DMR duration are important to predict TFR; although immunological control of CML plays a role, no immunological predictive phenotype is currently available. This guidance is intended as a practical tool to support physicians in decision making.
\end{abstract}

\section{Key Points}

In chronic-phase chronic myeloid leukemia, treatmentfree remission (TFR) after tyrosine kinase inhibitor therapy has become, with survival, a primary goal for virtually all patients.

The possibility of achieving TFR can no longer be denied to any patient, but some issues regarding the optimal selection of candidates remain unsolved.

We provide practical tools intended to facilitate the decision-making process and maximize the rate of TFR.

Fausto Castagnetti

fausto.castagnetti@unibo.it

Extended author information available on the last page of the article

\section{Introduction}

Tyrosine kinase inhibitors (TKIs) have drastically improved the outcome of patients with chronic-phase (CP) chronic myeloid leukemia (CML). Normal survival and good quality of life without life-long treatment are now the goals of therapy [1]. Treatment-free remission (TFR) after TKI therapy has become a feasible and safe option in selected CP-CML patients treated with imatinib mesylate (IM) or second-generation (2G) TKIs, such as nilotinib (the only TKI that can be discontinued by label [2]) and dasatinib. Beginning with the STIM1 (Stop Imatinib) study, a number of randomized controlled trials (RCTs) and real-world studies have demonstrated that $30-70 \%$ of patients achieving a sustained, stable deep molecular response (DMR) can successfully discontinue therapy and obtain TFR [2-28]. Albeit the inclusion criteria were heterogeneous, most studies relied on a minimum duration of TKI therapy of 3 years and a sustained DMR of $\geq 1$ year [1,29]. Long-term data indicate a TFR rate of 
$45 \%$ at 60 months $[5,30]$ and $39 \%$ at 77 months $[2,3]$ for patients treated with IM as first-line therapy or second-line after interferon (IFN), and of up to $56 \%$ at 60 months for patients receiving nilotinib or dasatinib as first- or second- line therapy [31].

All 2GTKIs have been tested as first-line treatment against IM in company-sponsored RCTs [32-34], but no data on direct comparisons are available yet [35]. No statistically significant survival benefit has been demonstrated for any specific TKI [1, 36, 37]. In the DASISION [33] and ENESTnd [32] trials, superiority of dasatinib and nilotinib was observed only in age-selected populations of young and adult individuals and, therefore, the results cannot be generalized.

The mean age of patients included in trials of TKI discontinuation was similar, between 49 and 63 years. Only in three studies age was shown to have a prognostic role in the maintenance of response, with an advantage for older patients [7, 25, 38]. Age is relevant, because younger patients more frequently express the desire for TFR. However, no age restriction can be set since older patients are just as interested in TFR as younger patients and have a higher probability of achieving a stable DMR [1,37].

According to the Gruppo Italiano Malattie Ematologiche dell'Adulto (GIMEMA) CML Working Party (WP) recommendations, both survival and TFR are therapeutic goals for patients with CP-CML, and the possibility of achieving TFR can no longer be denied to any patient. TFR should be considered as the primary goal for virtually all patients; treatment policies should be aimed at maximizing the TFR rate while limiting toxicity and costs [37]. However, other international recommendations are more conservative $[1,36]$ and, consequently, some grey areas remain.

To shed light on some controversial issues and provide practical tools to support physicians in their practice, four Italian experts selected the early prediction of DMR and TFR, the choice of first and later lines of therapy, the optimal frequency of molecular monitoring after the first 6 months of discontinuation, and TFR prognosis as topics that may have a remarkable impact on clinical practice. In collaboration with 17 more hematologists, four working groups were established. They discussed the available data in detail and shared their experience during four online meetings (one per topic) held in April/ May 2020. During a plenary meeting in July 2020, the panelists agreed on the final contents to include in the present paper and all of them approved this final version.

\section{Early Prediction of Deep Molecular Response (DMR) and Treatment-Free Remission (TFR): Is It Possible?}

Achievement of stable DMR (defined as at least a 4-log decrease in BCR-ABL1 transcript based on the International Scale [IS] [MR4) [39] for $>2$ years [40]) is a prerequisite to attempting TFR and, therefore, the early identification of DMR predictors is important. Thus far, gender, disease risk, transcript type, and achievement of an early molecular response (EMR) have been attributed a predictive role for attaining DMR in some, but not all, studies; still, their weight cannot be quantified.

\subsection{Gender}

In multivariate analysis, two studies reported a higher probability of achieving a stable DMR in female patients even though the reasons remain unclear [41, 42]. Moreover, in STIM1, female sex was associated with a higher rate of TFR at 12 months ( $70 \%$ vs. $46 \%$ in men) [2].

The panel agreed to consider female sex as predictive of achieving stable DMR.

\subsection{Disease Risk}

The Sokal score has long been used to assess the baseline risk of CML in patients treated with conventional chemotherapy, a-IFN and TKIs. However, according to the most recent recommendations [1, 37], the European Treatment and Outcome Study (EUTOS) long-term survival (ELTS) score should be preferred to assess the risk of progression at baseline and decide the first-line treatment. Despite the fact that the Sokal score and the ELTS score share the same parameters (i.e., hematologic data, spleen size and age), age has a lower negative prognostic impact on the Sokal score. Both scores predict the probability of achieving a major molecular response (MMR), DMR or deeper response [43, 44]. Interestingly, unlike the Sokal score, the ELTS score can predict the achievement of MMR (99\%, 87\% and 75\% in low-, intermediate- and high-risk patients, respectively; $P=0.001)$ and DMR $(82 \%, 61 \%$ and $50 \%$ in patients with a low, intermediate and high ELTS score, respectively; $P$ $=0.005)$ in CML patients older than 65 years treated with frontline IM or nilotinib therapy [43]. A recent retrospective study investigated the predictive value of the ELTS score with regard to treatment response in patients with CP-CML. Of the Sokal, Hasford, EUTOS and ELTS scores, EUTOS and ELTS predicted MMR at 12 months but ELTS was the only scoring system that predicted DMR at any time $(65.0 \%$, $43.7 \%$ and $23.5 \%$ in low- intermediate- and high-risk groups, respectively; $P=0.00006$ ).

Table 1 presents the studies assessing the role of the Sokal and ELTS score at diagnosis as predictors of TFR achievement and maintainance. The largest prospective trial conducted so far (EURO-SKI, $N=758$ ) failed to find a predictive role for the Sokal score or the ELTS score in maintaining an MMR 6 months after the discontinuation of TKI therapy [13]. Despite some experiences suggesting 
a relevant role of disease risk in predicting TFR [3, 21, 45], the GIMEMA and ELN recommendations, based on the EURO-SKI data [13], stated that the possibility of TFR cannot be denied to intermediate- or high-risk patients.

Low-risk patients have a higher probability of achieving a deeper response than intermediate- and high-risk patients, but it is still unclear whether low-risk patients have a higher probability of maintaining TFR after discontinuation.

The panel agreed that no patient, if eligible, should be excluded from a TFR based on the disease risk.

\subsection{Transcript Type}

The presence of a typical BCR-ABL1 transcript (i.e., e13a2 [b2a2] or e14a2 [b3a2]) is a prerequisite for proper molecular monitoring before and after cessation of TKI therapy $[1,45]$. In contrast, in the presence of an atypical transcript (found in nearly $2 \%$ of newly diagnosed CML patients [46]), TFR should not be attempted because of the lack of standardized monitoring methods $[1,36,45]$. Thus, although a recent report on seven patients harboring atypical transcripts has shown that treatment discontinuation may be attempted [47, 48], it cannot be recommended yet.

Most studies support the association of the presence of the e14a2 transcript with a faster achievement of a sustained DMR and with a higher rate and duration of TFR after both IM and 2GTKI therapy [41, 49-56] (Table 2). Moreover, in some studies, a better outcome has been reported for patients with the e $14 \mathrm{a} 2$ transcript if compared to patients with the e13a2 transcript $[49,50]$, but data were not conclusive.

Interestingly, the EUTOS study on 67 patients with newly diagnosed CML showed that the level of the e14a2 transcript was generally lower than that of the e13a 2 transcript (median $33.6 \%$, range $2.9-58.3 \%$ vs. $41.6 \%$, range $17.5-101.5$ ) and that the amplification of e14a 2 was on average $2.8 \%$ less efficient than that of e13a2 $(P=0.0026)$ [57]. This difference in the efficiency of amplification by real-time quantitative polymerase chain reaction (RT-qPCR) may contribute to explaining the differences in the time to achieve an MMR observed among patients with CML harboring the e13a2 and the e $14 \mathrm{a} 2$ transcripts. Recent studies comparing the performance of RT-qPCR and droplet digital PCR (ddPCR) in the quantification of both BCR-ABL1 transcripts reported higher levels of the e13a2 variant by RT-qPCR and no difference by ddPCR $[58,59]$, questioning the reliability of BCRABL1 measurement by RT-qPCR especially in patients with the e13a2 transcript. This issue is critical for the routine care of CML patients and the results of the ongoing multicenter study are eagerly awaited [57].
The panel agreed that the presence of a typical e14a2 transcript should be considered highly predictive of achieving stable DMR.

\subsection{Early Molecular Response}

EMR is defined as BCR-ABL ${ }^{\mathrm{IS}} \leq 10 \%$ at 3 months [60]. The rate of EMR at 3 months was between $60 \%$ and $80 \%$ after treatment with IM, $84 \%$ with dasatinib (vs. $64 \%$ with IM) [8] and 97\% with nilotinib [61]. Notably, patients attaining an EMR at 3 months were shown to reach a complete cytogenetic response (CCyR), an MMR and an MR4.5 by 5 years more frequently than those who did not [8], and had a higher probability of achieving and maintaining the TFR [42, 62-64].

The panel agreed to consider EMR as a predictor of a stable DMR.

Some studies have found that the decrease in BCR-ABL1 transcript levels - defined as BCR-ABL1 halving time (HT) — predicts clinical outcomes and MR regardless of the TKI [65-69]. A recent retrospective study [68] investigated whether the HT was able to discriminate which CML patients were likely to achieve DMR and could be considered for TKI discontinuation. HT was defined as a greater than twofold (if BCR-ABL1/ABL $1{ }^{\mathrm{IS}}$ levels were $\geq 0.01 \%$ ) or fivefold (if BCR-ABL1/ABL $1^{\mathrm{IS}}$ levels were $<0.01 \%$ ) decrease in two consecutive analyses. Results showed that the early (at 6 months) achievement of an MMR followed by a further BCR-ABL1 decrease to a DMR ( $\geq$ MR4.0) may be considered a selective parameter favoring the rapid identification of individuals potentially eligible for discontinuation of TKI therapy.

In the retrospective study by Shanmuganathan et al. [69], the HT at month 3 was significantly shorter in patients with sustained TFR than in those with molecular relapse, and was a significant predictor of sustained TFR. Based on the HT, patients were divided into quartiles $(\mathrm{Q} 1:<9.35$ days; $\mathrm{Q} 2$ : 9.35-13.95 days; Q3: 13.96-21.85 days; Q4: $>21.85$ days), with the probability of sustained TFR decreasing from $80 \%$ in $\mathrm{Q} 1$ to $4 \%$ in $\mathrm{Q} 4(\mathrm{P}<0.01)$. Notably, the late relapses had HT in Q3 and Q4, and all patients with HT in Q4 experienced molecular relapse during the follow-up [69].

The panel recognized the relevance of HT as a predictor of DMR but did not endorse its implementation in clinical practice because of the complexity of its calculation.

Table 3 reports the variables discussed above and their impact on TFR planning, In practice, the calculation of 
Table 1 Studies assessing the predictive value of the Sokal and ELTS score for TFR

\begin{tabular}{|c|c|c|c|c|c|c|}
\hline \multirow[t]{2}{*}{ Ref } & \multirow[t]{2}{*}{$N$} & \multirow[t]{2}{*}{ Outcome measure } & \multicolumn{4}{|l|}{ Disease risk } \\
\hline & & & Low & Intermediate & High & $P$ \\
\hline TWISTER [6] (Sokal) & 40 & $\begin{array}{l}\text { Rate of TFR } 3 \text { years after stopping } \\
\text { IM }\end{array}$ & $51.1 \%$ & $36.5 \%$ & $25.0 \%$ & \\
\hline \multirow[t]{3}{*}{ STIM1 long term [4] (Sokal) } & 100 & $\begin{array}{l}\text { Cumulative incidence of molecular } \\
\text { recurrence (SHR [95\%CI])-Uni- } \\
\text { variate analysis }\end{array}$ & Low + intermediate & & $2.01(0.98-4.11)$ & 0.05 \\
\hline & & $\begin{array}{l}\text { Cumulative incidence of molecular } \\
\text { recurrence (SHR [95\%CI])Multi- } \\
\text { variate analysis }\end{array}$ & Low + intermediate & & $2.22(1.11-4.442)$ & 0.024 \\
\hline & & $\begin{array}{l}\text { Cumulative incidence of molecular } \\
\text { recurrence over time }\end{array}$ & $\approx 58 \%$ & $\approx 82 \%$ & $\approx 82 \%$ & 0.048 \\
\hline $\begin{array}{l}\text { ENESTfreedom } 96 \text { weeks [22] } \\
\quad \text { (Sokal) }\end{array}$ & & Rate of TFR $(95 \% \mathrm{CI})$ & $61.3 \%(48.1-73.4)$ & $50.0 \%(35.5-64.5)$ & $28.6 \%(13.2-48.7)$ & \\
\hline \multirow[t]{3}{*}{ EURO-SKI [14] (Sokal and ELTS) } & 758 & $\begin{array}{l}\text { Probability of maintaining MMR } 6 \\
\text { months after TKI discontinuation } \\
\text { (OR }[95 \% \mathrm{CI}])\end{array}$ & & & & \\
\hline & & Sokal & Ref. & $0.91(0.60-1.37)$ & $0.90(0.52-1.55)$ & 0.88 \\
\hline & & ELTS & Ref. & $0.86(0.54-1.37)$ & $0.79(0.36-1.77)$ & 0.72 \\
\hline \multirow{14}{*}{$\begin{array}{l}\text { Castagnetti et al. (2018) [43] (Sokal } \\
\text { and ELTS) }\end{array}$} & & All patients & & & & \\
\hline & & Rate of MMR & & & & \\
\hline & & Sokal & $89 \%$ & $86 \%$ & $70 \%$ & $<0.001$ \\
\hline & & ELTS & $89 \%$ & $83 \%$ & $65 \%$ & $<0.001$ \\
\hline & & Rate of DMR & & & & \\
\hline & & Sokal & $68 \%$ & $63 \%$ & $49 \%$ & $<0.001$ \\
\hline & & ELTS & $73 \%$ & $53 \%$ & $42 \%$ & $<0.001$ \\
\hline & & Elderly (> 65 years) & & & & \\
\hline & & Rate of MMR & & & & \\
\hline & & Sokal & $94 \%$ & $88 \%$ & $83 \%$ & 0.471 \\
\hline & & ELTS & $100 \%$ & $87 \%$ & $75 \%$ & 0.001 \\
\hline & & Rate of DMR & & & & \\
\hline & & Sokal & $67 \%$ & $60 \%$ & $74 \%$ & 0.245 \\
\hline & & ELTS & $82 \%$ & $61 \%$ & $50 \%$ & 0.005 \\
\hline \multirow{4}{*}{$\begin{array}{l}\text { Italian observational study [26] } \\
\text { (Sokal) }\end{array}$} & 293 & Predictive value for molecular & Ref. & $0.74(0.47-1.17)$ & & 0.19 \\
\hline & & $\begin{array}{l}\text { relapse } \\
\text { HR }(95 \% \mathrm{CI}) \text { _-Univariate analysis }\end{array}$ & & & $1.66(0.98-2.81)$ & 0.06 \\
\hline & & $\begin{array}{l}\text { Predictive value for molecular } \\
\text { relapse } \\
\text { HR }(95 \% \mathrm{CI}) \text {-Multivariate } \\
\text { analysis }\end{array}$ & Ref. & $0.92(0.54-1.97)$ & & 0.76 \\
\hline & & & & & $2.07(1.16-3.71)$ & 0.01 \\
\hline \multirow{6}{*}{$\begin{array}{l}\text { Sato et al. } 2020 \text { [44] (Sokal and } \\
\text { ELTS) }\end{array}$} & & Rate of MMR by 12 months & & & & \\
\hline & & Sokal & $53.3 \%$ & $56.2 \%$ & $45.5 \%$ & 0.409 \\
\hline & & ELTS & $56.3 \%$ & $52.1 \%$ & $11.8 \%$ & 0.00137 \\
\hline & & Rate of DMR at any time & & & & \\
\hline & & Sokal & $63.3 \%$ & $56.2 \%$ & $50.9 \%$ & 0.223 \\
\hline & & ELTS & $65.0 \%$ & $43.7 \%$ & $23.5 \%$ & 0.000057 \\
\hline
\end{tabular}

Bold indicates statistically significant $P$-values $(<0.05)$

$N$ number of patients, TFR treatment-free remission, IM imatinib mesylate, SHR sub distribution hazard ratio, $95 \% C I$ 95\% confidence interval, $M M R$ major molecular response, ELTS European Treatment and Outcome Study long-term survival, OR odds ratio, pts patients, HR hazard ratio 
Table 2 Selection of studies reporting the association between the e14a2 transcript and molecular response and/or TFR as clinical outcome

\begin{tabular}{|c|c|c|c|c|}
\hline Ref & $N$ & Outcome measure & Results & $P$ \\
\hline \multirow[t]{4}{*}{ Bonifacio et al. (2015) [48] } & \multirow[t]{4}{*}{320} & \multicolumn{3}{|l|}{ Rate of stable MR4 (among pts with optimal response to IM) } \\
\hline & & At 3 months & $\begin{array}{l}\text { e13a2: } 23.2 \% \\
\text { e14a2: } 47.8 \% \\
\text { both: } 21 \%\end{array}$ & $\mathbf{0 . 0 0 3}^{\mathrm{a}}$ \\
\hline & & At 6 months & $\begin{array}{l}\text { e13a2: } 28.8 \% \\
\text { e14a2: } 48.6 \% \\
\text { both: } 33.3 \%\end{array}$ & $0.027^{\mathrm{a}}$ \\
\hline & & At 12 months & $\begin{array}{l}\text { e13a2: } 25.9 \% \\
\text { e14a2: } 53.7 \% \\
\text { both: } 40 \%\end{array}$ & $0.037^{\mathrm{a}}$ \\
\hline \multirow[t]{3}{*}{ Jain et al. (2016) [49] } & \multirow[t]{3}{*}{$\begin{array}{l}\text { e13a2: } 200 \\
\text { e14a2: } 196 \\
\text { both: } 85\end{array}$} & Cumulative rate of MMR & $\begin{array}{l}\text { e13a2: } 79 \% \\
\text { e14a2: } 91 \% \\
\text { both: } 95 \%\end{array}$ & 0.0001 \\
\hline & & Cumulative rate of MR4.5 & $\begin{array}{l}\text { e13a2: } 57 \% \\
\text { e14a2: } 79 \% \\
\text { both: } 80 \%\end{array}$ & 0.00001 \\
\hline & & MMR at 12 months: OR for e $14 \mathrm{a} 2(95 \% \mathrm{CI})$ & $\begin{array}{l}\text { e14a2: } 5.85(3.01-11.37) \\
\text { both: } 3.29(1.61-6.75)\end{array}$ & $<0.001$ \\
\hline \multirow[t]{4}{*}{ Castagnetti et al. (2017) [50] } & \multirow[t]{4}{*}{$\begin{array}{l}\text { e13a2: } 203 \\
\text { e14a2: } 290\end{array}$} & Median time to MMR & $\begin{array}{l}\text { e13a2: } 12 \text { months } \\
\text { e14a2: } 6 \text { months }\end{array}$ & 0.001 \\
\hline & & Overall estimated probability of MMR & $\begin{array}{l}\text { e13a2: } 83 \% \\
\text { e14a2: } 88 \%\end{array}$ & $<0.001$ \\
\hline & & Median time to MR4.0 & $\begin{array}{l}\text { e13a2: } 61 \text { months } \\
\text { e14a2: } 41 \text { months }\end{array}$ & \\
\hline & & Overall estimated probability of MR4.0 & $\begin{array}{l}\text { e13a2: } 52 \% \\
\text { e14a2: } 67 \%\end{array}$ & 0.001 \\
\hline \multirow[t]{4}{*}{ Claudiani et al. (2017) [51] } & \multirow[t]{4}{*}{$\begin{array}{l}\text { e13a2: } 27 \\
\text { e14a2: } 37\end{array}$} & Cumulative incidence of loosing MR3 $(95 \% \mathrm{CI})$ & $\begin{array}{l}\text { e13a2: } 64 \%(50-77) \\
\text { e14a2: } 35 \%(15-56)\end{array}$ & - \\
\hline & & $\begin{array}{l}\text { Cumulative incidence of MR3 loss over time for e14a2: HR } \\
(95 \% \mathrm{CI})\end{array}$ & & \\
\hline & & Univariate analysis & $0.4(0.18-0.85)$ & 0.019 \\
\hline & & Multivariate analysis & $0.38(0.18-0.84)$ & 0.016 \\
\hline Pagnano KBB et al. (2017) [52] & $\begin{array}{l}\text { e13a2: } 56 \\
\text { e14a2: } 94 \\
\text { both: } 20\end{array}$ & Rate of optimal MR (BCR-ABL levels $<10 \%$ ) at 3 months & $\begin{array}{l}\text { e13a2: } 60 \% \\
\text { e14a2: } 84 \% \\
\text { both: } 75 \%\end{array}$ & 0.02 \\
\hline \multirow[t]{2}{*}{$\begin{array}{l}\text { Breccia M et al. } 2018 \\
\text { [41] }\end{array}$} & \multirow[t]{2}{*}{$\begin{array}{l}\text { e13a2: } 97 \\
\text { e14a2: } 108 \\
\text { both: } 3\end{array}$} & Rate of MR4.5 & $\begin{array}{l}\text { e13a2: } 31 \% \\
\text { e14a2: } 43 \% \\
\text { both: } 42 \%\end{array}$ & 0.02 \\
\hline & & $\begin{array}{l}\text { Probability to achieve MR4.5-Multivariate analysis: HR } \\
(95 \% \text { CI }) \text { of e14a2 vs e13a2 }\end{array}$ & $1.6(1.3-2.0)$ & 0.03 \\
\hline \multirow[t]{2}{*}{ Shanmuganathan et al. (2018) [53] } & \multirow{2}{*}{$\begin{array}{l}\text { e13a2: } 35 \\
\text { e14a2: } 42 \\
\text { both: } 18\end{array}$} & Rate of TFR at 12 months & $\begin{array}{l}\text { e13a2: } 34 \% \\
\text { e14a2: } 65 \%\end{array}$ & 0.008 \\
\hline & & $\begin{array}{l}\text { Probability to remain in TFR at } 12 \text { months-Multivariate } \\
\text { analysis, HR }(95 \% \mathrm{CI}) \text { of e14a2/both vs e13a2 }\end{array}$ & $2.24(1.07-4.67)$ & 0.032 \\
\hline \multirow[t]{3}{*}{ D'Adda et al. (2019) [54] } & \multirow[t]{3}{*}{$\begin{array}{l}\text { e13a2: } 67 \\
\text { e14a2: } 106\end{array}$} & Rate of MR4 at 60 months & $\begin{array}{l}\text { e13a2: } 52.4 \% \\
\text { e14a2: } 82.2 \%\end{array}$ & 0.008 \\
\hline & & Rate of sustained DMR at 60 months & $\begin{array}{l}\text { e13a2: } 26.9 \% \\
\text { e14a2: } 47.2 \%\end{array}$ & 0.003 \\
\hline & & Rate of TFR after 12 months & $\begin{array}{l}\text { e13a2: } 22 \pm 14 \% \\
\text { e14a2: } 61 \pm 8 \%\end{array}$ & 0.005 \\
\hline \multirow[t]{2}{*}{ Genthon A et al. (2020) [55] } & \multirow[t]{2}{*}{$\begin{array}{l}\text { e13a2: } 51 \\
\text { e14a2: } 63\end{array}$} & Rate of MMR at 12 months & $\begin{array}{l}\text { e13a2: } 50.1 \% \\
\text { e14a2: } 66.7 \%\end{array}$ & 0.048 \\
\hline & & OR $(95 \% \mathrm{CI})$ & $3.25(1.30-8.18)$ & 0.01 \\
\hline
\end{tabular}

Bold indicates statistically significant $P$-values $(<0.05)$

${ }^{a}$ e14a2 vs e13a2 or e13a2/e14a2

$N$ number of patients, MR4 a 4-log decrease in BCR-ABL1 transcript based on the International Scale, IM imatinib mesylate, $M M R$ major molecular response, $O R$ odds ratio, $95 \%$ CI 95\% confidence interval, $H R$ hazard ratio, $M R$ molecular response, TFR treatment-free remission, $D M R$ deep molecular response 
BCR/ABL1 HT is complex and not yet standardized, therefore it was excluded from the tool.

\section{Criteria for the Choice of First and Subsequent Lines of Tyrosine Kinase Inhibitor (TKI) Therapy}

\subsection{Importance of Physician-Patient Communication}

Effective communication represents the basis in establishing and strengthening the therapeutic alliance between physicians and patients, allowing the patient's expectations, objectives and attitudes to be explored [70]. In the
Table 4 Choice of the first-line therapy according to the GIMEMA CML WP proposal [38]

\begin{tabular}{lllll}
\hline & $18-40$ years & $41-65$ years & 66-80 years & $>80$ year \\
\hline $\begin{array}{l}\text { Low ELTS } \\
\text { score }\end{array}$ & 2GTKIs & IM & IM & IM \\
$\begin{array}{c}\text { Int ELTS } \\
\text { score }\end{array}$ & 2GTKIs & 2GTKIs & IM-2GTKIs & IM \\
$\begin{array}{c}\text { High ELTS } \\
\text { score }\end{array}$ & 2GTKIs & 2GTKIs & IM-2GTKIs & IM \\
\hline
\end{tabular}

Bold indicates the grey zone in which therapy choice is more challenging

GIMEMA Gruppo Italiano Malattie EMatologiche dell'Adulto, ELTS

European Treatment and Outcome Study for CML (EUTOS) LongTerm Survival, 2GTKIs second-generation tyrosine kinase inhibitors, IM imatinib mesylate

Table 3 Tool summarising the factors that permit to plan a TFR: in orange, the conditions where a TFR is either not recommended or hardly achievable; in yellow and green, the intermediate and best possible scenarios, respectively

\begin{tabular}{|c|c|c|c|c|}
\hline Factor & ORANGE & YELLOW & GREEN & Notes \\
\hline \multicolumn{5}{|l|}{ AT DIAGNOSIS } \\
\hline Gender & & Male & Female & $\begin{array}{l}\text { Female sex is } \\
\text { predictive of a } \\
\text { higher DMR rate } \\
\text { vs male. Few } \\
\text { studies showed a } \\
\text { benefit in terms } \\
\text { of TFR duration }\end{array}$ \\
\hline Disease risk & & High & Non-high & $\begin{array}{l}\text { A high baseline } \\
\text { risk allows to } \\
\text { predict an inferior } \\
\text { DMR rate vs non- } \\
\text { high risk. The } \\
\text { duration of TFR is } \\
\text { not clearly risk- } \\
\text { related. The ELTS } \\
\text { score should be } \\
\text { preferred }\end{array}$ \\
\hline Type of transcript & Atypical transcript & e13a2 (b2a2) & e14a2 (b3a2) & $\begin{array}{l}\text { The e14a2 } \\
\text { transcript is } \\
\text { associated with } \\
\text { higher DMR rates } \\
\text { and more durable } \\
\text { TFR vs e13a2 }\end{array}$ \\
\hline \multicolumn{5}{|l|}{ DURING TREATMENT } \\
\hline MR at 3 months & $\begin{array}{l}\text { Level of transcript } \\
>10 \%\end{array}$ & $\begin{array}{l}\text { Level of transcript 1- } \\
10 \%\end{array}$ & Level of transcript $<1 \%$ & \multirow{2}{*}{$\begin{array}{l}\text { Failure of EMR at } \\
3 \text { and } 6 \text { months is } \\
\text { associated to very } \\
\text { low chances of } \\
\text { achieving a DMR }\end{array}$} \\
\hline MR at 6 months & $\begin{array}{l}\text { Level of transcript } \\
>1 \%\end{array}$ & $\begin{array}{l}\text { Level of transcript } \\
0.1-1 \%\end{array}$ & $\begin{array}{l}\text { Level of transcript } \\
<0.1 \%\end{array}$ & \\
\hline $\begin{array}{l}\text { TKI, overall treatment } \\
\text { duration }\end{array}$ & $<3$ years & $\begin{array}{l}\text { 3-5 years (IM) } \\
3-4 \text { years (2GTKIs) }\end{array}$ & $\begin{array}{l}>5 \text { years }(\mathrm{IM}) \\
>4 \text { years }(2 \mathrm{GTKIS})\end{array}$ & \multirow[t]{2}{*}{$\begin{array}{l}\text { "Green } \\
\text { milestones" } \\
\text { predict optimal } \\
\text { TFR duration }\end{array}$} \\
\hline DMR duration & $\begin{array}{l}\text { MR4.5: }<1.0 \text { year } \\
\text { MR4.0: }<2 \text { years }\end{array}$ & $\begin{array}{l}\text { MR4.5: } 1-2 \text { years } \\
\text { MR4.0: } 2-3 \text { years }\end{array}$ & $\begin{array}{l}\text { MR4.5: } \geq 2 \text { years } \\
\text { MR4.0: } \geq 3 \text { years }\end{array}$ & \\
\hline
\end{tabular}

$D M R$ deep molecular response, TFR treatment-free remission, ELTS European Treatment and Outcome Study long-term survival, $M R$ molecular response, $E M R$ early molecular response, $T K I$ tyrosine-kinase inhibitor, IM imatinib mesylate, $2 G T K I$ second-generation TKI 
context of TFR, despite the clear advantages, treatment discontinuation may raise concerns in patients because of fear of the unknown (individual probability of disease relapse) [71-76] and has been associated with anxiety and depression [77]. Thus, the physician's ability to effectively communicate with patients, providing adequate information to reassure and motivate them, plays a central role [2]. This is particularly important when the treatment choice is controversial (see below). In the case of older patients, the involvement of caregivers is essential.

The panel endorsed the ELN 2020 recommendations [1] advising consideration of TFR after careful discussion with the patient, highlighting the importance of shared decision making.

\subsection{Choosing the First-Line Therapy}

TKIs are the standard of care for the first-line treatment of CPCML, but current international recommendations, including the ELN recommendations, do not provide simple criteria to choose a specific inhibitor for each individual patient $[1,36$, 45]. In view of treatment discontinuation, the first practical suggestion on how to choose the first-line therapy comes from the GIMEMA CML WP, who suggest that the patient's age (i.e., $18-40$ years; $41-65$ years; $66-80$ years; $>80$ years) and the ELTS score should be considered [37] (Table 4).
The panel endorsed this proposal acknowledging that the choice is more challenging in some grey zones (i.e., lowrisk patients aged 41-65 years and intermediate-/highrisk individuals aged 66-80 years), where the choice of first-line treatment needs a careful evaluation of each individual patient [37].

\subsection{The Choice in Controversial Cases}

The panel proposed to consider a number of patients' and drugs' characteristics to steer the choice of therapy in controversial cases (Table 5).

The panel acknowledged the importance of considering the type and severity of concomitant diseases [37, 78]; the patient's comorbidities should be carefully evaluated and managed to minimize the risk of TKI toxicity, also in the long term [79]. Moreover, the panel included the patient's expectations, individual attitudes and personal objectives among the factors to be taken into account when deciding whether TFR is a priority. A minor role was attributed to drug costs and physicians' personal experience.

The panel acknowledged that, when the treatment goal is TFR, a longer therapy duration increases the chance of achieving it, even with the 2GTKIs [13].

Consequently, before TKI discontinuation, a dose reduction could be considered to reduce the side effects while

Table 5 Tool to help steer the choice of therapy in first and second line (and beyond)

\begin{tabular}{lll}
\hline & Factors to be considered for the choice of therapy & Second line (and beyond) \\
\cline { 2 - 3 } & First line & Reason of switch (Int vs. Fail/Warn) \\
Patient & Disease risk (ELTS score, CCA in Ph+) & BCR-ABL1 mutations ${ }^{\mathrm{a}}$ \\
& Age & Type of first-line TKI (IM vs. 2GTKIs) \\
& Comorbidities (type, severity) & Comorbidities (severity, type) \\
& Personal expectations and objectives & Age \\
& & Personal expectations and objectives \\
& & Potency (efficacy; time to response) \\
Drug & Potency (efficacy; time to response) & Side Effects (long-term safety) \\
Endpoints & Side Effects (long-term safety) & Overall survival \\
& Overall survival & Quality of life \\
& Treatment-free remission & Treatment-free remission \\
\hline
\end{tabular}

ELTS European Treatment and Outcome Study for CML (EUTOS) Long-Term Survival, CCA clonal chromosomal abnormalities, Ph+ Philadelphia-positive, Int intolerance, Fail failure (i.e., loss of MMR), Warn warning (i.e., carefully consider the current treatment for continuation or change based on the patient' characteristics comorbidities and tolerance), TKI tyrosine-kinase inhibitor, IM imatinib mesylate, 2GTKI secondgeneration TKIs

${ }^{a}$ As reported in the GIMEMA recommendations [38], of the 35 most frequent BCR-ABL1 kinase domain mutations associated with TKI resistance: all but five confer resistance to imatinib: M244V, L248V, G250E, Q252H, Y253H, E255V/K, L273M, D276G, T277A, E279K, F311L, T315I, F317L/V/I/C, M351T, E355G, F359C/I/V, E379K, L384M, L387M/F, H398R/P, E459K and F486S; Y253H, E255V/K, T315I and F359C/I/V to nilotinib; V299L, T315I/A, and F317L/V/I/C to dasatinib; E255V/K, V299L and T315I to bosutinib; T315M/L to ponatinib 
continuing treatment [80-84]. The non-randomized, phase 2 De-Escalation and Stopping Treatment with Imatinib, Nilotinib, or Dasatinib (DESTINY) study evaluated the deescalation to half the standard dose for 12 months followed by discontinuation for 24 months with frequent RT-qPCR monitoring [83]. In patients with stable MR4, 1 year of deescalation before stopping resulted in a 2-year relapse-free survival of $72 \%$, with improvement of common treatmentrelated symptoms [83]. Further insights, not only on TFR success but also on the incidence of the TKI withdrawal syndrome, will be provided by the ongoing Italian phase 2 , prospective multicentre De-escAlation and discontinuation of Nilotinib ThErapy (DANTE) trial, evaluating the rate of TFR in selected CP-CML patients treated with nilotinib at half the standard dose during a consolidation period of 12 months, followed by complete cessation of therapy [84].

\subsection{When to Switch the TKI}

Approximately $40-50 \%$ of the patients on TKI therapy undergo a switch from first- to second-line therapy. The decision to change depends on the treatment response at 3, 6, 12 and 24 months. As shown in Table 6, the criteria for response definition (i.e., optimal, failure or warning) are clear and are similar across the ELN 2020 recommendations [1] and the GIMEMA proposal [37]. The only difference relies on the fact that the ELN definitions refer to treatment changes aimed at achieving optimal survival, whereas the GIMEMA response criteria aim at the achievement of a TFR. In particular, for the 24-month milestone the GIMEMA WP has given a more stringent definition of 'optimal' response, warning and failure [1, 37].

The panel endorsed the GIMEMA WP criteria [37].

\subsection{Choosing the Second-Line Therapy}

In keeping with other international recommendations, the GIMEMA WP did not provide clear indications on which TKI should be preferred for second-line therapy.

The panel ackowledged that the choice of second-line treatment (and beyond) is influenced by the reasons for switching, the presence and the type of BCR-ABL mutations, and the type of first-line TKI, considering that, in the case of resistance or warning to first-line treatment, the subsequent chances of reaching a TFR are very low or low, respectively [23, 31].

The variables to be considered in this setting are summarized in Table 5.
Table 6 Comparison of response criteria $[1,36,38]$

\begin{tabular}{lllll}
\hline & RESPONSE & GIMEMA 2019 & NCCN 2019 & ELN 2020 \\
\hline \multirow{6}{*}{3 months } & Optimal & $\leq 10$ & $\leq 10$ & $\leq 10$ \\
& Warning & - & $>10$ & $>10$ \\
& Failure & $>10$ (con- & - & - \\
& & firmed) & & \\
6 months & Optimal & $\leq 1$ & $\leq 10$ & $\leq 1$ \\
& Warning & $1-10$ & - & $1-10$ \\
& Failure & $>10$ & $>10$ & $>10$ \\
12 months & Optimal & $\leq 0.1$ & $\leq 1$ & $\leq 0.1$ \\
& Warning & $0.1-1$ & $1-10$ & $0.1-1$ \\
& Failure & $>1$ & $>10$ & $>1$ \\
24 months & Optimal & $\leq 0.01$ & $\leq 1$ & $\leq 0.1$ \\
& Warning & $0.1-0.01$ & - & $0.1-1$ \\
& Failure & $>0.1$ & $>1$ & $>1$ \\
\hline
\end{tabular}

GIMEMA Gruppo Italiano Malattie EMatologiche dell'Adulto, ELN European LeukemiaNet, NCCN National Comprehensive Cancer Network

The panel endorsed the 2020 ELN recommendations [1]: In the case of intolerance, any TKI can be used; in the case of resistance to IM, the choice is a $2 \mathrm{GTKI}$, whereas in the case of resistance to a $2 \mathrm{GTKI}$, the choice is ponatinib.

\section{The Frequency of Monitoring During TFR}

\subsection{The Frequency of Molecular Monitoring After Discontinuation: Focus on the Second Semester}

After cessation of therapy, the frequency of monitoring must ensure patient safety, promptly detecting possible loss of MMR and allowing resumption of therapy before the loss of cytogenetic or hematological responses. Albeit relapse occurs predominantly within the first 6 months of TFR [3, $13,47]$, the response may be lost even 2 years after discontinuation [85]: data from 128 patients included in the prospective discontinuation trial A-STIM indicate that very late recurrence (i.e., $>2$ years after discontinuation) occurs in nearly $14 \%$ of patients. Moreover, patients with a stable MR4.5 had a $100 \%$ probability of remaining in TFR for more than 2 years versus $65.4 \%$ in those with an unstable remission [85]. Notably, the kinetics of relapse differs between patients relapsing very early or those who do not [86].

The first indications on the frequency of monitoring were, and are, rather stringent [87]. In clinical practice, it is expected that the frequency of monitoring will be prolonged. Current guidelines consistently recommend monitoring patients more frequently during TFR than during therapy 
(i.e., monthly by RT-qPCR for at least 6 months $[1,36,37]$ ), but there is no agreement about the frequency of monitoring after the first 6 months $[1,36]$, and neither did the GIMEMA WP reach a consensus [37].

Shanmuganathan et al. [88] evaluated different monitoring algorithms. They found that performing molecular tests every 2 months for the first 6 months and every 3 months thereafter in patients maintaining MR4.5 provided the best balance between reduced testing and shorter delays in detecting relapse and resuming TKI [88]. A lower frequency (i.e., every 3 months) resulted in many patients loosing cytogenetic and hematological responses, which is not acceptable [88]. The need for a stringent follow-up for early diagnosis of MMR loss has been confirmed in a sub-analysis of an Italian observational study, which retrospectively investigated the modalities of molecular monitoring performed in 227 patients with CML in a real-life setting [25, 47]. By month $6,46 \%$ of patients had three or fewer molecular assessments and $77.5 \%$ of those off treatment $(\mathrm{N}=71)$ who relapsed, did so during the first 6 months. The authors calculated that if a 3-month monitoring schedule was adopted, $>50 \%$ of patients would have experienced a delay in the detection of MR loss up to month 6, very few patients between month 6 and 12 , and even fewer afterwards [47].

The panel agreed that, given the absence of factors reliably predicting the stability of TFR during the first 6 months, the monthly monitoring is mandatory. In difficult situations (i.e., advanced age, comorbidities, difficulty accessing the lab), it is advisable to avoid offering the TFR. After the first 6 months, the monitoring frequency depends on the careful evaluation of what happened before, and can be adjusted based on the stability of MR4.5 (Table 7).

At present, it is not possible to establish whether any baseline factor can influence the frequency of monitoring.

\subsection{Turnaround Time and Possible Role of Digital Droplet Polymerase Chain Reaction (PCR)}

Current indications on the turnaround time (TAT) of the RT-qPCR test results are different: within 15 days for the National Comprehensive Cancer Network (NCCN) guidelines [36], within 4 weeks for Hughes et al. [89], and "rapidly" for the ELN 2020 recommendations [1]. During the first 6 months off treatment, it is mandatory to receive the results within 4 weeks, that is before the next blood withdrawal. In Italian real-life, the TAT is about 3 weeks, which is adequate in the first 6 months. Afterwards, the mean TAT of the reference lab must be considered to ensure prompt intervention in the case of MMR loss.
Table 7 Frequency of molecular monitoring in case of stable and unstable MR4.5 maintained during the first 6 months after discontinuation. After month 6, patients with unstable MR4.5 must be monitored at closer intervals than those with a stable MR4.5. When personalizing the frequency of monitoring, it is important to consider the turnaround time (TAT) of the reference lab

\begin{tabular}{lll}
\hline $\begin{array}{l}\text { Months after TKI } \\
\text { cessation }\end{array}$ & MR4.5 up to month 6 \\
\cline { 2 - 3 } & Stable & Unstable \\
\hline $0-6$ & Monthly & Monthly \\
$7-12$ & Every 2-3 months & Every 1.5-2 months \\
$>12$ & Every 4 months & Every 3 months \\
\hline
\end{tabular}

TKI tyrosine-kinase inhibitor, $M R 4.5$ molecular response defined as a 4.5-log decrease in BCR-ABL1 transcript based on the International Scale, Stable MR4.5 up to month 6 confirmed MR4.5 in all QPCR tests performed in the first 6 months after discontinuation

The panel agreed that if a TAT of 4 weeks cannot be assured, the interval between the molecular tests can be extended up to the higher limit of the intervals reported in Table 7.

Novel monitoring techniques with improved sensitivity for detection of residual disease, such as ddPCR, could help to refine the selection of candidates for TFR and provide useful information during TFR. Experiences in this field are discordant. In a cohort of 142 CML patients monitored for a median time of 24 months, ddPCR was more sensitive and accurate than standard RT-qPCR in measuring minimal residual disease [90]; among the 111 patients who discontinued treatment, a threshold value of 0.468 BCR-ABL1 copies/ $\mu \mathrm{L}$ at TKI stop was able to predict the maintenance of TFR [90]. In contrast, RT-qPCR was unable to discriminate patients with a higher risk of MMR loss after discontinuation [90]. Similarly, the evaluation of BCR-ABL1 by a combination of DNA and RNA measurement during DMR maintenance before TKI cessation was more effective than standard RT-qPCR performed on cDNA in predicting the success of TFR [91]. Interestingly, a recent update of the Italian discontinuation ISAV study showed that ddPCR was able to detect increasing BCR-ABL1 values in most non-relapsing patients after 36 months after discontinuation, reinforcing the need for regular long-term monitoring of TFR patients in order to detect late progressions [92].

However, other studies failed to identify differences in the sensitivity for BCR-ABL1 detection between $\mathrm{PPCR}$ and ddPCR [93, 94].

The panel agreed that standard RT-qPCR is the technique of choice during TFR. ddPCR is a potential alternative to RT-qPCR $[95,96]$ but not yet standard- 
ized [97]. Therefore, its implementation in clinical practice is not yet advisable.

\section{The Prognosis of TFR}

\subsection{Duration of Therapy}

Therapy duration is one of the most relevant prognostic factors for the success of TFR. The EURO-SKI trial demonstrated that in patients receiving first-line IM, longer treatment duration was associated with a continuous, per-year increase in the probability of maintaining MMR at 6 months (odds ratio [OR] per year: $1.14,95 \%$ confidence interval [CI] $1.05-1.23 ; P=0.0010$ ) [13]. Recently, duration of nilotinib therapy before the start of TFR was identified as the only significant predictor of a durable TFR in a pooled analysis of data from ENESTfreedom and ENESTop [98]. The authors found that each 1-month increase in therapy duration was associated with a $3.6 \%$ (95\% CI 1.5-5.8) increase in the odds of durable TFR at week 24 [98].

The GIMEMA CML WP agreed that, to ensure safety and avoid disease progression, the minimum duration of treatment should be 3 years with a 2GTKI and 5 years with IM, but no consensus was reached on the definition of 'optimal' duration [37]. The ELN 2020 recommendations, published soon after the GIMEMA proposal, acknowledged a duration of TKI therapy $>5$ years with IM and $>4$ years for 2 GTKI among the 'minimal' requirements (i.e., stop allowed) for therapy cessation. A duration $>5$ years was defined as 'optimal' (i.e., stop recommended for consideration) [1]. These differences in the number of years considered by the GIMEMA CML WP and ELN are due to the lack of definitive, prospectively validated cut-off values; still, the longer the duration of therapy, the higher the likelihood of maintaining MMR at 6 months [13].

The panel endorsed the minimum and optimal criteria reported in the ELN recommendations [1] (Table 3).

\subsection{Duration of the DMR}

Similar to therapy duration, no unequivocal cut-off values are available for DMR duration; indeed, those provided by the GIMEMA CML WP and ELN differ from each other [1, 37]. In patients treated with IM as first-line therapy, longer DMR duration (OR per year: $1.13,95 \%$ CI $1.04-1.23$; $P=$ 0.0032 ) was associated with increasing probability of MMR maintenance at 6 months [13].

In clinical practice, a score to predict the success of TFR would be very useful, but despite many attempts, at present none is available. Claudiani et al. proposed a score including duration of MR4, previous TKI resistance, age at diagnosis and transcript type [99]. Nonetheless, the score has not been independently validated and it does not include any indication on the minimal duration of DMR.

The panel agreed with the minimal and optimal criteria of DMR duration reported in the 2020 ELN recommendations [1] (Table 3).

\subsection{Immunological Factors: Is It Possible to Develop an Immunological Score?}

The mechanisms underpinning the lack of overt relapse in about $50 \%$ of patients off treatment are still unclear. A possible role has been attributed to host factors, such as the effector-mediated immune surveillance (impaired in CML patients before TKI therapy and restored by the use of TKIs) and/or to the leukemic stem cells (LSCs) $[81,100,101]$. However, although the peripheral blood cell populations involved in TFR are well characterized, the LSC compartment and target antigens are not well known [102], and to date there is no immunological predictive phenotype that may be used in clinical practice.

The immunological control of CML changes throughout the different phases of the disease (pre-TKI therapy, during TKI therapy and during TFR), with immunoescape failing progressively and immunosurveillance prevailing upon TKI therapy [100]. Immunoescape is unanimously defined as the result of the activity of programmed cell death protein 1-positive $\mathrm{T}$ cells, regulatory $\mathrm{T}$ cells (Tregs) and myeloidderived suppressor cells belonging to the BCR/ABL1 clone. Conversely, natural killer (NK) cells and cytotoxic T lymphocytes are responsible for immunosurveillance. Over time, during TKI therapy, the system first reaches equilibrium and then, in the TFR phase, immunosurveillance prevails over immunoescape [100].

Regarding the control of disease at the LSC level the panel discussed the possible existence of a particular antigen able to stimulate the immune system, leading to disease control and culminating in the achievement and maintenance of TFR. The findings from Bocchia et al. [103] do not support the hypothesis that $\mathrm{CD} 26$ might be the actual target of immunosurveillance: indeed, the authors found circulating CD26+ LSCs in a relevant proportion of CP-CML patients during first-line TKI therapy and in TFR, with similar numbers (on therapy: median 0.014 cells $/ \mu \mathrm{L}$; range $0.0012-0.66$ cells $/ \mu \mathrm{L}$; in TFR: median 0.015 cells $/ \mu \mathrm{L}$; range $0.006-0.76$ cells $/ \mu \mathrm{L}$ ) [103]. Moreover, the number of residual LSCs did not correlate with the BCR-ABL1/ABL1 ${ }^{\text {IS }}$ ratio [103].

The panel agreed that there are no convincing data supporting a key role of any particular antigen in the immune control of the minimal residual disease. 
Other published scores were analyzed but the data were not conclusive: (1) the 'effector-suppressor' score [104], based on the absolute count of NK cells, Tregs and MSDCs at the time of discontinuation; (2) a score based on individual immunologic configurations (i.e., quiescent LSCs, proliferating LSCs and effector cells, with a complex mathematical model) [105]; (3) a score based on proteomics and (inflammatory) cytokines [106].

Finally, a recent study conducted on 19 patients reported detection of BCR/ABL1 on genomic DNA from sorted B lymphocytes, suggesting that the lineage-specific assessment of minimal residual disease in individual patients may contribute to predicting the success of TFR [107].

The panel acknowledged the lack of tools based on immunological parameters in clinical practice for the prediction of TFR and that more research is needed. The panel agreed that the total duration of TKI treatment and DMR duration are the pivotal factors to predict the stability of TFR. Other parameters, namely the transcript type, the rapidity of the MR, the Sokal or ELTS risk score, gender and age, may significantly influence the success of TFR, but data are not conclusive.

\section{Conclusions and Future Perspectives}

TFR is a complex matter and, despite the large number of clinical trials conducted thus far, several issues remain unsolved. Of the current recommendations and proposals, only those from the GIMEMA CML WP focused on TFR as a primary goal of therapy.

In this paper, we addressed the topics that we deemed as the most urgent based on our clinical practice experience (early prediction of DMR and TFR; criteria for first and subsequent line therapy choice; monitoring of residual disease after discontinuation; prognosis of TFR). The originality (and main strength) of our work, compared with similar recent papers reviewing the literature and discussing controversial points, resides in the practical tools provided for each topic, which are intended to facilitate the decisionmaking process in daily practice.

However, a few points remained unsolved. In the future, it will be important to: (1) clarify whether the amplification efficiency of the e13a2 and e $14 \mathrm{a} 2$ transcripts is really different, because this would have an impact on their predictive value of DMR; (2) assess the role of first or subsequent-line of treatment with 2G-3GTKIs and new drugs in maximizing the probability of TFR without increasing toxicity; (3) implement novel sensitive techniques for the standardized monitoring of residual disease, such as ddPCR; (4) elucidate the mechanisms behind the immunological control of CML, in order to identify possible markers to predict the risk of relapse after TKI cessation through an immunological score.

Acknowledgements Medical writing support and editorial assistance was provided by Clara Ricci, $\mathrm{PhD}$ (Edra SpA, Milan, Italy), and unconditionally funded by Novartis Farma SpA.

Funding Open access funding provided by Alma Mater Studiorum - Università di Bologna within the CRUI-CARE Agreement. This project was supported by Novartis Farma SpA. Medical writing support and editorial assistance was provided by Clara Ricci, $\mathrm{PhD}$ (Edra SpA, Milan, Italy), and unconditionally funded by Novartis Farma SpA

\section{Declarations}

Conflicts of interest Fausto Castagnetti has received consultancy fees and honoraria from Novartis, Incyte, Pfizer and Bristol Myers Squibb; Gianni Binotto has received honoraria and speaker fees from Novartis, Pfizer, Incyte, BMS-Celgene; Isabella Capodanno has received honoraria and speaker fees from Novartis, Pfizer and Incyte; Atto Billio declares no conflicts of interest; Elisabetta Calistri declares no conflicts of interest; Francesco Cavazzini has received honoraria and speaker fees from Novartis, Pfizer and Incyte; Monica Crugnola has received honoraria from Novartis and Incyte; Antonella Gozzini has received honoraria from Novartis, Incyte and Bristol Myers Squibb; Gabriele Gugliotta has received honoraria/consultancy fees from Novartis, Pfizer and Incyte; Mauro Krampera has received honoraria/consultancy fees from Novartis; Alessandro Lucchesi has received honoraria from Novartis, Incyte and Pfizer; Anna Merli declares no conflicts of interest; Maria Cristina Miggiano declares no conflicts of interest; Claudia Minotto has received honoraria for serving on the advisory board from Novartis; Monica Poggiaspalla declares no conflicts of interest; Marzia Salvucci declares no conflicts of interest; Barbara Scappini has received honoraria and speaker fees from Novartis, Amgen Sanofi, Jazz and Incyte; Mario Tiribelli has received honoraria and speaker fees from Novartis, Pfizer and Incyte; Elena Trabacchi declares no conflicts of interest; Gianantonio Rosti has received consultancy fees and honoraria from Novartis, Incyte, Pfizer and Bristol Myers Squibb; Sara Galimberti has received honoraria from Novartis, Incyte and Pfizer; Massimiliano Bonifacio has received consultancy fees from Novartis, Pfizer, Incyte and Amgen.

Ethics approval Not applicable.

Consent to participate Not applicable.

Consent for publication Not applicable.

Availability of data and material Not applicable.

Code availability Not applicable.

Author contributions Conceptualization: FC and GR; FC, GB, IC, SG and $\mathrm{MB}$ performed the literature search and drafted the manuscript. All the authors discussed/interpreted the literature data and critically revised the work.

Open Access This article is licensed under a Creative Commons Attribution-NonCommercial 4.0 International License, which permits any non-commercial use, sharing, adaptation, distribution and reproduction in any medium or format, as long as you give appropriate credit to the original author(s) and the source, provide a link to the Creative Commons licence, and indicate if changes were made. The images or other third party material in this article are included in the article's Creative 
Commons licence, unless indicated otherwise in a credit line to the material. If material is not included in the article's Creative Commons licence and your intended use is not permitted by statutory regulation or exceeds the permitted use, you will need to obtain permission directly from the copyright holder. To view a copy of this licence, visit http://creativecommons.org/licenses/by-nc/4.0/.

\section{References}

1. Hochhaus A, Baccarani M, Silver RT, Schiffer C, Apperley JF, Cervantes F, et al. European LeukemiaNet 2020 recommendations for treating chronic myeloid leukemia. Leukemia. 2020;34:966-84.

2. Mahon F-X, Réa D, Guilhot J, Guilhot F, Huguet F, Nicolini $F$, et al. Discontinuation of imatinib in patients with chronic myeloid leukaemia who have maintained complete molecular remission for at least 2 years: the prospective, multicentre Stop Imatinib (STIM) trial. Lancet Oncol. 2010;11:1029-35.

3. Etienne G, Guilhot J, Rea D, Rigal-Huguet F, Nicolini F, Charbonnier A, et al. Long-Term Follow-Up of the French Stop Imatinib (STIM1) Study in Patients With Chronic Myeloid Leukemia. J Clin Oncol. 2017;35:298-305.

4. Rousselot P, Charbonnier A, Cony-Makhoul P, Agape P, Nicolini $\mathrm{FE}$, Varet B, et al. Loss of major molecular response as a trigger for restarting tyrosine kinase inhibitor therapy in patients with chronic-phase chronic myelogenous leukemia who have stopped imatinib after durable undetectable disease. J Clin Oncol. 2014;32:424-30.

5. Ross DM, Branford S, Seymour JF, Schwarer AP, Arthur C, Yeung DT, et al. Safety and efficacy of imatinib cessation for CML patients with stable undetectable minimal residual disease: results from the TWISTER study. Blood. 2013;122:515-22.

6. Hehlmann R, Müller MC, Lauseker M, Hanfstein B, Fabarius A, Schreiber A, et al. Deep molecular response is reached by the majority of patients treated with imatinib, predicts survival, and is achieved more quickly by optimized high-dose imatinib: results from the randomized CML-study IV. J Clin Oncol. 2014;32:415-23.

7. Mori S, Vagge E, le Coutre P, Abruzzese E, Martino B, Pungolino $\mathrm{E}$, et al. Age and dPCR can predict relapse in CML patients who discontinued imatinib: the ISAV study. Am J Hematol. 2015;90:910-4.

8. Cortes JE, Saglio G, Kantarjian HM, Baccarani M, Mayer J, Boqué C, et al. Final 5-year study results of DASISION: the dasatinib versus imatinib study in treatment-naïve chronic myeloid leukemia patients trial. J Clin Oncol. 2016;34:2333-40.

9. Hochhaus A, Saglio G, Hughes TP, Larson RA, Kim D-W, Issaragrisil S, et al. Long-term benefits and risks of frontline nilotinib vs imatinib for chronic myeloid leukemia in chronic phase: 5-year update of the randomized ENESTnd trial. Leukemia. 2016;30:1044-54.

10. Lee S-E, Choi SY, Song H-Y, Kim S-H, Choi M-Y, Park JS, et al. Imatinib withdrawal syndrome and longer duration of imatinib have a close association with a lower molecular relapse after treatment discontinuation: the KID study. Haematologica. 2016;101:717-23.

11. Mahon F-X, Nicolini FE, Noël M-P, Escoffre M, Charbonnier A, Rea D, et al. Preliminary report Of The STIM2 study: a multicenter stop imatinib trial for chronic phase chronic myeloid leukemia de novo patients on imatinib. Blood. 2013;122(21):654.

12. Takahashi N, Tauchi T, Kitamura K, Miyamura K, Saburi Y, Miyata Y, et al. Around 70\% of Japanese CML patients could stop imatinib according to a-STIM criteria: the JALSG-STIM213 Study. Blood. 2015;126(23):4035.

13. Saussele S, Richter J, Guilhot J, Gruber FX, Hjorth-Hansen H, Almeida A, et al. Discontinuation of tyrosine kinase inhibitor therapy in chronic myeloid leukaemia (EURO-SKI): a prespecified interim analysis of a prospective, multicentre, non-randomised, trial. Lancet Oncol. 2018;19:747-57.

14. Breccia M, Foà R. Current Information and Recommendations on the Discontinuation of TKI Inhibitors in Chronic Myeloid Leukemia. Curr Oncol Rep. 2018;20:23.

15. Rea D, Nicolini FE, Tulliez M, Guilhot F, Guilhot J, GuerciBresler A, et al. Discontinuation of dasatinib or nilotinib in chronic myeloid leukemia: interim analysis of the STOP 2G-TKI study. Blood. 2017;129(7):846-54.

16. Okada M, Imagawa J, Tanaka H, Nakamae H, Hino M, Murai K, et al. Final 3-year results of the dasatinib discontinuation trial in patients with chronic myeloid leukemia who received dasatinib as a second-line treatment. Clin Lymphoma Myeloma Leuk. 2018;18:353-360.e1.

17. Kumagai T, Nakaseko C, Nishiwaki K, Yoshida C, Ohashi K, Takezako N, et al. Discontinuation of dasatinib after deep molecular response for over 2 years in patients with chronic myelogenous leukemia and the unique profiles of lymphocyte subsets for successful discontinuation: a prospective, multicenter Japanese Trial (D-STOP Trial). Blood. 2016;128(22):791.

18. Shah NP, Paquette R, Müller MC, Saussele $S$, Garcìa-Gutiérrez V, Jiménez-Velasco A, et al. Treatment-free remission (TFR) in patients with chronic phase chronic myeloid leukemia (CML-CP) and in stable deep molecular response (DMR) to dasatinib - the dasfree study. Blood.2016;128(22):1895.

19. Shah NP, García-Gutiérrez V, Jiménez-Velasco A, Larson S, Saussele S, Rea D, et al. Dasatinib discontinuation in patients with chronic-phase chronic myeloid leukemia and stable deep molecular response: the DASFREE study. Leuk Lymphoma. 2020;61:650-9.

20. Hochhaus A, Masszi T, Giles FJ, Radich JP, Ross DM, Gómez Casares MT, et al. Treatment-free remission following frontline nilotinib in patients with chronic myeloid leukemia in chronic phase: results from the ENESTfreedom study. Leukemia. 2017;31:1525-31.

21. Ross DM, Masszi T, Gómez Casares MT, Hellmann A, Stentoft $\mathrm{J}$, Conneally E, et al. Durable treatment-free remission in patients with chronic myeloid leukemia in chronic phase following frontline nilotinib: 96-week update of the ENESTfreedom study. J Cancer Res Clin Oncol. 2018;144:945-54.

22. Giles FJ, Masszi T, Gómez Casares MT, Hellmann A, Stentoft J, Conneally E, et al. Treatment-free remission (TFR) following frontline (1L) nilotinib (NIL) in patients (pts) with chronic myeloid leukemia in chronic phase (CML-CP): 192week data from the ENESTfreedom study. J Clin Oncol. 2019;37(15_Suppl):7013.

23. Mahon F-X, Boquimpani C, Kim D-W, Benyamini N, Clementino NCD, Shuvaev V, et al. Treatment-free remission after second-line nilotinib treatment in patients with chronic myeloid leukemia in chronic phase: results from a single-group, phase 2 , open-label Study. Ann Intern Med. 2018;168:461-70.

24. Hughes TP, Boquimpani C, Takahashi N, Benyamini N, Clementino NCD, Shuvaev V, et al. ENESTop 192-week results: Treatment-free remission (TFR) in patients (pts) with chronic myeloid leukemia in chronic phase (CML-CP) after stopping second-line (2L) nilotinib (NIL). J Clin Oncol. 2019;37(15_Suppl):7005.

25. Fava C, Rege-Cambrin G, Dogliotti I, Cerrano M, Berchialla P, Dragani M, et al. Observational study of chronic myeloid leukemia Italian patients who discontinued tyrosine kinase inhibitors in clinical practice. Haematologica. 2019;104(8):1589-96. 
26. Kwok M, Shenouda A, Duncan N, Hasan Y, Ewing J, Raghavan $\mathrm{M}$, et al. Outcomes following treatment discontinuation iN CML: real-world experience from 3 regional UK centres: PB1946. HemaSphere. 2019;3:884.

27. Abruzzese E, Bosi A, Breccia M, D’Adda M, Di Renzo N, Liberati AM, et al. Treatment patterns in patients with chronicphase chronic myeloid leukaemia in routine clinical practice: the SIMPLICITY Italian Population. Mediterr J Hematol Infect Dis. 2019;11:e2019025.

28. Dengler J, Tesch H, Jentsch-Ullrich K, Gerhardt A, Schulte C, Lipke J, et al. Treetment-free remission in real-world chronic myeloid leukemia patients: Insights from German clinical hematology practices. EHA Library. Kiani A. 06/14/19; 266218; PF418. https://library.ehaweb.org/eha/2019/24th/266218/alexa nder.kiani.treatment-free.remission.in.real-world.chronic.myelo id.html?f=listing \%3D0\%2Abrowseby\%3D8\%2Asortby\%3D1\% 2Asearch\%3Dkiani.

29. Ross DM, Hughes TP. Treatment-free remission in patients with chronic myeloid leukaemia. Nat Rev Clin Oncol. 2020;17:493-503.

30. Ross DM, Pagani IS, Shanmuganathan N, Kok CH, Seymour JF, Mills AK, et al. Long-term treatment-free remission of chronic myeloid leukemia with falling levels of residual leukemic cells. Leukemia. 2018;32:2572-9.

31. Rea D, Nicolini FE, Tulliez M, Rousselot P, Gardembas M, Etienne G, et al. Prognostication of molecular relapses after dasatinib or nilotinib discontinuation in chronic myeloid leukemia (CML): a FI-LMC STOP 2G-TKI study update. Blood. 2019;134(1_Suppl):30.

32. Saglio G, Kim D-W, Issaragrisil S, le Coutre P, Etienne G, Lobo $\mathrm{C}$, et al. Nilotinib versus imatinib for newly diagnosed chronic myeloid leukemia. N Engl J Med. 2010;362:2251-9.

33. Kantarjian H, Shah NP, Hochhaus A, Cortes J, Shah S, Ayala M, et al. Dasatinib versus imatinib in newly diagnosed chronic-phase chronic myeloid leukemia. N Engl J Med. 2010;362:2260-70.

34. Cortes JE, Gambacorti-Passerini C, Deininger MW, Mauro MJ, Chuah C, Kim D-W, et al. Bosutinib versus imatinib for newly diagnosed chronic myeloid leukemia: results from the randomized BFORE Trial. J Clin Oncol. 2018;36:231-7.

35. Gruppo Italiano Malattie EMatologiche dell'Adulto. Sustained Treatment-free Remission in BCR-ABL+ Chronic Myeloid Leukemia: a Prospective Study Comparing Nilotinib Versus Imatinib With Switch to Nilotinib in Absence of Optimal Response. SUSTRENIM Study-GIMEMA CLM1415 [Internet]. clinicaltrials. gov; 2017 Oct. Report No.: NCT02602314. https://clinicaltrials. gov/ct2/show/NCT02602314.

36. Radich JP, Deininger M, Abboud CN, Altman JK, Berman E, Bhatia R, et al. Chronic myeloid leukemia, Version 1.2019, NCCN clinical practice guidelines in oncology. J Natl Compr Canc Netw. 2018;16:1108-35.

37. Baccarani M, Abruzzese E, Accurso V, Albano F, Annunziata $\mathrm{M}$, Barulli $\mathrm{S}$, et al. Managing chronic myeloid leukemia for treatment-free remission: a proposal from the GIMEMA CML WP. Blood Adv. 2019;3:4280-90.

38. Shah NP, García Gutiérrez JV, Jiménez-Velasco A, Larson S, Saussele S, Rea D, et al. Updated 18-month results from dasfree: a study evaluating dasatinib discontinuation in patients (Pts) with chronic myeloid leukemia in chronic phase (CML-CP) and deep molecular response (DMR). Blood. 2018;132:4253.

39. Cross NCP, White HE, Müller MC, Saglio G, Hochhaus A. Standardized definitions of molecular response in chronic myeloid leukemia. Leukemia. 2012;26:2172-5.

40. Hughes T, Deininger M, Hochhaus A, Branford S, Radich $\mathrm{J}$, Kaeda $\mathrm{J}$, et al. Monitoring CML patients responding to treatment with tyrosine kinase inhibitors: review and recommendations for harmonizing current methodology for detecting BCR-ABL transcripts and kinase domain mutations and for expressing results. Blood. 2006;108:28-37.

41. Breccia M, Molica M, Colafigli G, Massaro F, Quattrocchi L, Latagliata R, et al. Prognostic factors associated with a stable MR4.5 achievement in chronic myeloid leukemia patients treated with imatinib. Oncotarget. 2018;9:7534-40.

42. Branford S, Yeung DT, Ross DM, Prime JA, Field CR, Altamura $\mathrm{HK}$, et al. Early molecular response and female sex strongly predict stable undetectable BCR-ABL1, the criteria for imatinib discontinuation in patients with CML. Blood. 2013;121:3818-24.

43. Castagnetti F, Gugliotta G, Breccia M, Stagno F, Specchia G, Levato L, et al. The use of EUTOS long-term survival score instead of Sokal score is strongly advised in elderly chronic myeloid leukemia Patients. Blood. 2018;132(1_Suppl):44.

44. Sato E, Iriyama N, Tokuhira M, Takaku T, Ishikawa M, Nakazato $\mathrm{T}$, et al. The EUTOS long-term survival score predicts diseasespecific mortality and molecular responses among patients with chronic myeloid leukemia in a practice-based cohort. Cancer Med. 2020;9:8931-9.

45. Hochhaus A, Saussele S, Rosti G, Mahon F-X, Janssen JJWM, Hjorth-Hansen $\mathrm{H}$, et al. Chronic myeloid leukaemia: ESMO Clinical Practice Guidelines for diagnosis, treatment and followup. Ann Oncol. 2017;28:iv41-51.

46. Baccarani M, Castagnetti F, Gugliotta G, Rosti G, Soverini S, Albeer A, et al. The proportion of different BCR-ABL1 transcript types in chronic myeloid leukemia. An international overview. Leukemia. 2019;33:1173-83.

47. Dragani M, Rege-Cambrin G, Gottardi E, Daraio F, Caocci G, Aguzzi C, et al. Treatment free remission in chronic myeloid leukemia patients harboring atypical BCR-ABL1 transcripts. EHA Library. Dragani M. 06/15/19; 266796; PS1179

48. Schäfer V, White HE, Gerrard G, Möbius S, Saussele S, Franke $\mathrm{G}-\mathrm{N}$, et al. Assessment of individual molecular response in chronic myeloid leukemia patients with atypical BCR-ABL1 fusion transcripts: recommendations by the EUTOS cooperative network. J Cancer Res Clin Oncol. 2021;147(10):3081-89.

49. Bonifacio M, Scaffidi L, Binotto G, De Marchi F, Maino E, Calistri E, et al. Predictive factors of stable deep molecular response in chronic myeloid leukemia patients treated with imatinib standard dose: a study from the Gruppo Triveneto LMC. Blood. 2015;126(23):597.

50. Jain P, Kantarjian H, Patel KP, Gonzalez GN, Luthra R, Kanagal Shamanna R, et al. Impact of BCR-ABL transcript type on outcome in patients with chronic-phase CML treated with tyrosine kinase inhibitors. Blood. 2016;127:1269-75.

51. Castagnetti F, Gugliotta G, Breccia M, Iurlo A, Levato L, Albano $\mathrm{F}$, et al. The BCR-ABL1 transcript type influences response and outcome in Philadelphia chromosome-positive chronic myeloid leukemia patients treated frontline with imatinib. Am J Hematol. 2017;92:797-805.

52. Claudiani S, Apperley JF, Gale RP, Clark R, Szydlo R, Deplano $\mathrm{S}$, et al. E14a2 BCR-ABL1 transcript is associated with a higher rate of treatment-free remission in individuals with chronic myeloid leukemia after stopping tyrosine kinase inhibitor therapy. Haematologica. 2017;102:e297-9.

53. Pagnano KBB, Miranda EC, Delamain MT, Duarte GO, de Paula EV, Lorand-Metze I, et al. Influence of BCR-ABL transcript type on outcome in patients with chronic-phase chronic myeloid leukemia treated with imatinib. Clin Lymphoma Myeloma Leuk. 2017; $17: 728-33$.

54. Shanmuganathan N, Branford S, Yong ASM, Hiwase DK, Yeung DT, Ross DM, et al. The e13a2 BCR-ABL1 transcript is associated with higher rates of molecular recurrence after 
treatment-free remission attempts: retrospective analysis of the adelaide cohort. Blood. 2018;132(1_Suppl):1731.

55. D'Adda M, Farina M, Schieppati F, Borlenghi E, Bottelli C, Cerqui E, et al. The e13a2 BCR-ABL transcript negatively affects sustained deep molecular response and the achievement of treatment-free remission in patients with chronic myeloid leukemia who receive tyrosine kinase inhibitors. Cancer. 2019;125:1674-82.

56. Genthon A, Nicolini FE, Huguet F, Colin-Gil C, Berger M, Saugues S, et al. Influence of major BCR-ABL1 transcript subtype on outcome in patients with chronic myeloid leukemia in chronic phase treated frontline with nilotinib. Oncotarget. 2020;11:2560-70.

57. Machova Polakova K, Salmon M, Zizkova H, Gottschalk A, Motlova E, Jurcek T, et al. Individual molecular response evaluation on both DNA and mRNA BCR-ABL1 level diminished differences in time to molecular response achievement between CML patients with E13A2 vs E14A2 transcript type. HemaSphere. 2020;4:351

58. Kjaer L, Skov V, Andersen MT, Aggerholm A, Clair P, Gniot M, et al. Variant-specific discrepancy when quantitating BCR-ABL1 e13a2 and e14a2 transcripts using the Europe Against Cancer qPCR assay. Eur J Haematol. 2019;103:26-34.

59. Bernardi S, Bonifacio M, Iurlo A, Zanaglio C, Tiribelli M, Binotto G, et al. "Variant-specific discrepancy when quantitating BCR-ABL1 e13a2 and e14a2 transcripts using the Europe Against Cancer qPCR assay.” Is dPCR the key? Eur J Haematol. 2019;103:272-3.

60. Baccarani M, Deininger MW, Rosti G, Hochhaus A, Soverini $\mathrm{S}$, Apperley JF, et al. European LeukemiaNet recommendations for the management of chronic myeloid leukemia: 2013. Blood. 2013;122:872-84.

61. Hochhaus A, Rosti G, Cross NCP, Steegmann JL, le Coutre P, Ossenkoppele G, et al. Frontline nilotinib in patients with chronic myeloid leukemia in chronic phase: results from the European ENEST1st study. Leukemia. 2016;30:57-64.

62. Marin D, Hedgley C, Clark RE, Apperley J, Foroni L, Milojkovic D, et al. Predictive value of early molecular response in patients with chronic myeloid leukemia treated with first-line dasatinib. Blood. 2012;120:291-4.

63. Breccia M, Molica M, Colafigli G, Massaro F, Alimena G. Early molecular response in chronic myeloid leukemia and halving time: Latest evidences. Leuk Res. 2016;48:20-5.

64. Hanfstein B, Müller MC, Hehlmann R, Erben P, Lauseker M, Fabarius A, et al. Early molecular and cytogenetic response is predictive for long-term progression-free and overall survival in chronic myeloid leukemia (CML). Leukemia. 2012;26:2096-102.

65. Branford S, Yeung DT, Parker WT, Roberts ND, Purins L, Braley JA, et al. Prognosis for patients with CML and $>10 \%$ BCR-ABL1 after 3 months of imatinib depends on the rate of BCR-ABL1 decline. Blood. 2014;124:511-8.

66. Iriyama N, Fujisawa S, Yoshida C, Wakita H, Chiba S, Okamoto $\mathrm{S}$, et al. Shorter halving time of BCR-ABL1 transcripts is a novel predictor for achievement of molecular responses in newly diagnosed chronic-phase chronic myeloid leukemia treated with dasatinib: Results of the D-first study of Kanto CML study group. Am J Hematol. 2015;90:282-7.

67. Fava C, Rege-Cambrin G, Dogliotti I, Gottardi E, Berchialla P, Di Gioacchino B, et al. Early BCR-ABL1 reduction is predictive of better event-free survival in patients with newly diagnosed chronic myeloid leukemia treated with any tyrosine kinase inhibitor. Clin Lymphoma Myeloma Leuk. 2016;16(Suppl):S96-100.

68. Pennisi MS, Stella S, Vitale SR, Puma A, Di Gregorio S, Romano $\mathrm{C}$, et al. BCR-ABL1 doubling-times and halving-times may predict CML response to tyrosine kinase inhibitors. Front Oncol. 2019;9:764.

69. Shanmuganathan N, Pagani IS, Ross DM, Park S, Yong AS, Braley JA, et al. Early BCR-ABL1 kinetics are predictive of subsequent achievement of treatment-free remission in chronic myeloid leukemia. Blood. 2020;137(9):1196-207.

70. Pinto RZ, Ferreira ML, Oliveira VC, Franco MR, Adams R, Maher CG, et al. Patient-centred communication is associated with positive therapeutic alliance: a systematic review. J Physiother. 2012;58:77-87.

71. Villemagne Sanchez LA, O'Callaghan C, Gough K, Hall K, Kashima Y, Seymour JF, et al. Patient perceptions of treatmentfree remission in chronic myeloid leukemia. Leuk Lymphoma. 2018;59:406-15.

72. Sanford D, Kyle R, Lazo-Langner A, Xenocostas A, Chin-Yee I, Howson-Jan K, et al. Patient preferences for stopping tyrosine kinase inhibitors in chronic myeloid leukemia. Curr Oncol. 2014;21:e241-249.

73. Breccia M, Efficace F, Sica S, Abruzzese E, Cedrone M, Turri $\mathrm{D}$, et al. Adherence and future discontinuation of tyrosine kinase inhibitors in chronic phase chronic myeloid leukemia. A patientbased survey on 1133 patients. Leuk Res. 2015;39:1055-9.

74. Goldberg SL, Savona M, Mauro MJ. Considerations for successful treatment-free remission in chronic myeloid leukemia. Clin Lymphoma Myeloma Leuk. 2018;18:98-105.

75. Lou J, Huang J, Wang Z, Wen B, Tu C, Huang W, et al. Chronic myeloid leukemia patients and treatment-free remission attitudes: a multicenter survey. Patient Prefer Adherence. 2018;12:1025-32.

76. Boquimpani CM, Szczudlo T, Mendelson E, Benjamin K, Masszi $\mathrm{T}$. Attitudes and perceptions of patients (pts) with chronic myeloid leukemia in chronic phase (CML-CP) toward treatment-free remission (TFR). Blood. 2014;124(21):4547.

77. Sogawa R, Kimura S, Yakabe R, Mizokami Y, Tasaki M, Sueoka-Aragane N, et al. Anxiety and depression associated with tyrosine kinase inhibitor discontinuation in patients with chronic myeloid leukemia. Int J Clin Oncol. 2018;23(5):974-9.

78. Uemura M, Imataki O, Kawachi Y, Kawakami K, Hoshijima Y, Matsuoka A, et al. Charlson comorbidity index predicts poor outcome in CML patients treated with tyrosine kinase inhibitor. Int J Hematol. 2016;104:621-7.

79. Steegmann JL, Baccarani M, Breccia M, Casado LF, GarcíaGutiérrez V, Hochhaus A, et al. European LeukemiaNet recommendations for the management and avoidance of adverse events of treatment in chronic myeloid leukaemia. Leukemia. 2016;30:1648-71.

80. Copland M. Is there a role for dose modification of TKI therapy in CML? Curr Hematol Malig Rep. 2019;14:337-45.

81. Kunbaz A, Eskazan AE. An alternative way-tyrosine kinase inhibitor (TKI) de-escalation-to discontinue TKIs in order to achieve treatment-free remission. Expert Rev Hematol. 2019;12:477-80.

82. Cayssials E, Torregrosa-Diaz J, Gallego-Hernanz P, Tartarin F, Systchenko T, Maillard N, et al. Low-dose tyrosine kinase inhibitors before treatment discontinuation do not impair treatmentfree remission in chronic myeloid leukemia patients: Results of a retrospective study. Cancer. 2020;126:3438-47.

83. Clark RE, Polydoros F, Apperley JF, Milojkovic D, Rothwell $\mathrm{K}$, Pocock C, et al. De-escalation of tyrosine kinase inhibitor therapy before complete treatment discontinuation in patients with chronic myeloid leukaemia (DESTINY): a non-randomised, phase 2 trial. Lancet Haematol. 2019;6:e375-83.

84. DANTE study. A phase II, Single-arm, Multicenter study of full treatment-free remission in patients with chronic myeloid leukemia in chronic phase treated with nilotinib in first-line therapy who have achieved a sustained, deep molecular response for 
at least 1 year [Internet]. clinicaltrials.gov; 2020 Jun. Report No.: NCT03874858. https://clinicaltrials.gov/ct2/show/NCT03 874858.

85. Rousselot P, Loiseau C, Delord M, Cayuela JM, Spentchian M. Late molecular recurrences in patients with chronic myeloid leukemia experiencing treatment-free remission. Blood Adv. 2020;4:3034-40.

86. Rea D, Mahon F-X. How I manage relapse of chronic myeloid leukaemia after stopping tyrosine kinase inhibitor therapy. Br J Haematol. 2018;180:24-32.

87. Tasigna SPC. Tasigna [Internet]. European Medicines Agency. [cited 2020 Nov 20]. https://www.ema.europa.eu/en/medicines/ human/EPAR/tasigna.

88. Shanmuganathan N, Braley JA, Yong AS, Hiwase DK, Yeung DT, Ross DM, et al. Modelling the safe minimum frequency of molecular monitoring for CML patients attempting treatmentfree remission. Blood. 2019;134(1):85-9.

89. Hughes TP, Ross DM. Moving treatment-free remission into mainstream clinical practice in CML. Blood. 2016;128:17-23.

90. Bernardi S, Malagola M, Zanaglio C, Polverelli N, Dereli Eke E, D'Adda M, et al. Digital PCR improves the quantitation of DMR and the selection of CML candidates to TKIs discontinuation. Cancer Med. 2019;8:2041-55.

91. Machova Polakova K, Zizkova H, Zuna J, Motlova E, Hovorkova L, Gottschalk A, et al. Analysis of chronic myeloid leukaemia during deep molecular response by genomic PCR: a traffic light stratification model with impact on treatment-free remission. Leukemia. 2020;34:2113-24.

92. Diral E, Mori S, Antolini L, Abruzzese E, le Coutre P, Martino $\mathrm{B}$, et al. Increased tumor burden in Chronic Myeloid Leukemia patients after 36 months of imatinib discontinuation. Blood. 2020;136(19):2237-40.

93. Alikian M, Whale AS, Akiki S, Piechocki K, Torrado C, Myint T, et al. RT-qPCR and RT-digital PCR: a comparison of different platforms for the evaluation of residual disease in chronic myeloid leukemia. Clin Chem. 2017;63:525-31.

94. Cortés AA, Olmedillas S, Serrano-López J, Lainez-González D, Castaño T, Iñiguez R, et al. Comparison of droplet digital pcr versus $\mathrm{qPCR}$ measurements on the international scale for the molecular monitoring of chronic myeloid leukemia patients. Mol Diagn Ther. 2020;24:593-600.

95. Kockerols CCB, Valk PJM, Levin M-D, Pallisgaard N, Cornelissen JJ, Westerweel PE. Digital PCR for BCR-ABL1 quantification in CML: current applications in clinical practice. Hemasphere. 2020;4:e496.

96. Atallah E, Schiffer CA, Radich JP, Weinfurt KP, Zhang M-J, Pinilla-Ibarz J, et al. Assessment of outcomes after stopping tyrosine kinase inhibitors among patients with chronic myeloid leukemia: a nonrandomized clinical trial. JAMA Oncol. 2021;7:42-50.

97. Coccaro N, Tota G, Anelli L, Zagaria A, Specchia G, Albano F. Digital PCR: a reliable tool for analyzing and monitoring hematologic malignancies. Int J Mol Sci. 2020;21(9):3141.

98. Radich JP, Hochhaus A, Giles FJ, Ross DM, Saglio G, Hughes TP, et al. Analyses of predictors of durable treatment-free remission in patients with chronic myeloid leukemia in chronic phase following frontline or second-line nilotinib. Blood. 2019;134(1_Suppl):2932.

99. Claudiani S, Metelli S, Kamvar R, Szydlo R, Khan A, Byrne $\mathrm{J}$, et al. Introducing a predictive score for successful treatment free remission in chronic myeloid leukemia (CML). Blood. 2019;134(1_Suppl):26.

100. Hughes A, Yong ASM. Immune effector recovery in chronic myeloid leukemia and treatment-free remission. Front Immunol. 2017;8:469.

101. Galimberti S, Petrini M, Baratè C, Ricci F, Balducci S, Grassi $\mathrm{S}$, et al. Tyrosine kinase inhibitors play an antiviral action in patients affected by chronic myeloid leukemia: a possible model supporting their use in the fight against SARS-CoV-2. Front Oncol. 2020;10:1428.

102. Houshmand M, Blanco TM, Circosta P, Yazdi N, Kazemi A, Saglio G, et al. Bone marrow microenvironment: The guardian of leukemia stem cells. World J Stem Cells. 2019;11:476-90.

103. Bocchia M, Sicuranza A, Abruzzese E, Iurlo A, Sirianni S, Gozzini A, et al. Residual peripheral blood CD26+ leukemic stem cells in chronic myeloid leukemia patients during TKI therapy and during treatment-free remission. Front Oncol. 2018;8:194.

104. Irani YD, Hughes A, Clarson J, Kok CH, Shanmuganathan N, White DL, et al. Successful treatment-free remission in chronic myeloid leukaemia and its association with reduced immune suppressors and increased natural killer cells. Br J Haematol. 2020;191:433-41.

105. Hähnel T, Baldow C, Guilhot J, Guilhot F, Saussele S, Mustjoki $\mathrm{S}$, et al. Model-based inference and classification of immunologic control mechanisms from TKI cessation and dose reduction in patients with CML. Cancer Res. 2020;80:2394-406.

106. Söderlund S, Persson I, Ilander M, Guilhot J, Hjorth-Hansen $\mathrm{H}$, Koskenvesa $\mathrm{P}$, et al. Plasma proteomics of biomarkers for inflammation or cancer cannot predict relapse in chronic myeloid leukaemia patients stopping tyrosine kinase inhibitor therapy. Leuk Res. 2020;90:106310.

107. Pagani IS, Dang P, Saunders VA, Grose R, Shanmuganathan N, $\mathrm{Kok} \mathrm{CH}$, et al. Lineage of measurable residual disease in patients with chronic myeloid leukemia in treatment-free remission. Leukemia. 2020;34:1052-61. 


\section{Authors and Affiliations}

\section{Fausto Castagnetti ${ }^{1,2} \cdot$ Gianni Binotto $^{3} \cdot$ Isabella Capodanno $^{4}$. Atto Billio ${ }^{5}$ Elisabetta Calistri ${ }^{6}$. Francesco Cavazzini ${ }^{7} \cdot$ Monica Crugnola ${ }^{8}$. Antonella Gozzini ${ }^{9} \cdot$ Gabriele Gugliotta $^{1} \cdot$ Mauro Krampera $^{10}$. Alessandro Lucchesi ${ }^{11}$. Anna Merli ${ }^{12}$. Maria Cristina Miggiano ${ }^{13}$. Claudia Minotto ${ }^{14}$. Monica Poggiaspalla ${ }^{11}$. Marzia Salvucci ${ }^{15} \cdot$ Barbara Scappini $^{16} \cdot$ Mario Tiribelli $^{17}$. Elena Trabacchi ${ }^{18} \cdot$ Gianantonio Rosti $^{19} \cdot$ Sara Galimberti $^{20}$. Massimiliano Bonifacio ${ }^{10}$}

1 Istituto di Ematologia “Seràgnoli”, IRCCS Azienda Ospedaliero-Universitaria di Bologna, Bologna, Italy

2 Dipartimento di Medicina Specialistica, Diagnostica e Sperimentale, Università di Bologna, Bologna, Italy

3 Hematology and Clinical Immunology Unit, University of Padua, Padua, Italy

4 Hematology Unit, Azienda Unità Sanitaria Locale-IRCCS, Reggio Emilia, Italy

5 Hematology and Bone Marrow Transplantation, Ospedale di Bolzano, Bolzano, Italy

6 Ospedale di Treviso, Treviso, Italy

7 Hematology Unit, Azienda Ospedaliero-Universitaria "S.Anna", Ferrara, Italy

8 Hematology Unit and BMT, Azienda Ospedaliero Universitaria, Parma, Italy

9 Department of Cellular Therapies and Transfusion Medicine, Azienda Ospedaliero-Universitaria Careggi, Florence, Italy

10 Section of Hematology and Bone Marrow Transplant Unit, Department of Medicine, University of Verona, Verona, Italy

11 Hematology Unit, IRCCS Istituto Romagnolo per lo Studio dei Tumori (IRST) "Dino Amadori”, Meldola, Italy
12 Hematology Unit, Ospedale Infermi Rimini, AUSL Romagna, Rimini, Italy

13 Hematology Department, San Bortolo Hospital, Vicenza, Italy

14 Medical Oncology and Onco-Hematology Unit, AULSS 3 Serenissima distretto di Dolo-Mirano, Venice, Italy

15 Hematology Unit, Oncology and Hematology Department, Ospedale Civico, Ravenna, Italy

16 Hematology Unit, Azienda Ospedaliero-Universitaria Careggi, Florence, Italy

17 Division of Hematology and BMT, Department of Medical Area, University of Udine, Udine, Italy

18 Hematology Unit and BMT Center, Ospedale G. Saliceto, Piacenza, Italy

19 Scientific Direction, IRCCS Istituto Romagnolo per lo Studio dei Tumori (IRST) "Dino Amadori”, Meldola, FC, Italy

20 Section of Hematology, Department of Clinical and Experimental Medicine, University of Pisa, Pisa, Italy 